\title{
GIÁ TRI CỦA SIÊU ÂM TRONG CHẨN ĐOÁN VIÊM PHỔI CÓ BIẾN CHỨNG Ở TRẺ EM
}

\section{TÓM TẮT}

Mục tiêu: Xác định giá trị của siêu âm phổi trong chẩn đoán viêm phổi có biến chứng ở trẻ em (đối chiếu với $X$-quang cắt lớp vi tính là tiêu chuẩn vàng chẩn đoán). Đối tượng, phương pháp: Dân số chon mẫu là những đối tượng bệnh nhân ở trên được chẩn đoán viêm phổi tai khoa Hồ hấp và các khoa khác tai Bệnh viện Nhi đồng I - Thành phố Hồ Chí Minh từ tháng 9/2018 đến tháng 7/2019. Phương pháp nghiên cứu: nghiên cứu hồi cứu kết hợp tiến cứu (mô tả ca bệnh). So sánh kết quả chẩn đoán của siêu âm với Xquang cắt lớp vi tính là tiêu chuẩn vàng chẩn đoán. Kết quả: Siêu âm trong chẩn đoán viêm phổi biến chứng có độ nhạy, độ đặc hiệu cao (94,3\% và $75 \%)$. Độ nhạy, độ đặc hiệu của siêu âm trong chẩn đoán từng loại biến chứng của viêm phổi là cao: tràn dịch màng phổi (đô̂ nhạy: 95\%, độ đặc hiệu: 93,3\%), tràn khí màng phổi (độ nhay: 83,3\%, đô đặc hiệu: 100\%), xẹp phổi (độ nhạy: 95,7\%, độ đặc hiệu: $100 \%$ ) và viềm phổi hoại tử (độ nhạy: 93,3\%, độ đặc hiệu: $100 \%)$. Kết luận: Siêu âm phổi là phương tiện chẩn đoán hình ảnh không xâm lấn có giá trị kinh tể cao so với các phương tiện chẩn đoán hình ảnh khác như chụp X-quang cắt lớp vi tính ngực, Chụp cộng hưởng từ....

Tư khoá: Siêu âm, viêm phổi, biến chứng

\section{SUMMARY \\ VALUE OF LUNG ULTRASOUND IN DIAGNOSIS OF COMPLICATED PNEUMONIA IN CHILDREN}

Objectives: To determine the value of lung ultrasound in the diagnosis of complicated pneumonia in children (compared with CT scan as the diagnostic gold standard). Subjects and methods: The pediatric patients who were diagnosed with pneumonia at the Respiratory Department and other departments at Children's Hospital I - Ho Chi Minh City from September 2018 to September 2018. 7/2019. Methods: Retrospective combined prospective study (case description). Comparing the diagnostic results of ultrasound with CT scan as the diagnostic gold standard. Results: Ultrasound in the diagnosis of complicated pneumonia has high sensitivity and specificity (94.3\% and $75 \%$ ). The sensitivity and specificity of ultrasound in the diagnosis of each type of pneumonia complication is high: pleural effusion (sensitivity: $95 \%$, specificity: $93.3 \%$ ), pneumothorax (sensitivity: 95\%, specificity: $93.3 \%$, specificity: $100 \%$ ), atelectasis (sensitivity: $95.7 \%$, specificity:

*Trường Đại học Y Phạm Ngọc Thạch, Tp Hồ Chí Minh Chịu trách nhiệm chính: Ngô Minh Xuân

Email: xuanlien62@pnt.edu.vn

Ngày nhận bài: 01.3.2021

Ngày phản biên khoa họ: 26.4.2021

Ngày duyệt bài: 10.5.2021
Ngô Minh Xuân*

$100 \%$ ) and necrotizing pneumonia (sensitivity: $93.3 \%$, specificity: 100\%). Conclusion: Lung ultrasound is a non-invasive imaging tool with high economic value compared to other imaging methods such as chest x-ray, computed tomography, magnetic resonance imaging.

Keywords: Ultrasound, pneumonia, complications

\section{I. ĐăTT VẤN ĐỀ}

Viêm phổi là một bệnh phổ biến trên thế giới và là nguyên nhân gây tử vong hàng đầu ở trẻ dưới 5 tuổi. Hàng năm có khoảng 156 triêu trường hợp mắc mới, trong đó chủ yếu ở các nước đang phát triển, số lượng bệnh nhi tử vong do viêm phổi là 1,9 triêu trường hợp [5].

Viêm phổi có diễn biến từ nhe đến nặng. Trong trường hợp nghiêm trọng, bệnh có thể gây ra những biển chứng nguy hiểm như: nhiễm khuẩn huyết, áp xe phổi, tràn dịch màng phổi, tràn khí màng phổi, viêm phổi hoại tử... và hậu quả cuối cùng có thể dấn tới tử vong nếu không điêu tri kịp thời [7]. Đây là môt bênh lý phức tap, bênh cảnh lâm sàng đa dạng, phu thuộc vào các nguyên nhân gây bệnh cũng như các tổn thương cơ bản của hệ thống hô hấp và bệnh lý nền của bệnh nhân. Tỷ lệ tử vong, tỷ lệ biến chứng phụ thuộc vào các nhóm nguyên nhân gây bệnh.

Việc chẩn đoán viêm phổi ở trẻ em, cũng như biến chứng của viêm phổi có vai trò đặc biệt quan trọng trong điều trị và tiên lượng bệnh. Hiện nay, chẩn đoán viêm phổi và biến chứng của viêm phổi chủ yếu dựa vào bệnh sử, triệu chứng lâm sàng như sốt, ho, nhị thở nhanh, khó thở, khò khè... Khi trẻ được nghi ngờ viêm phổi thì X-quang ngực vẫn là phương tiện chẩn đoán hình ảnh đầu tiên được lựa chọn để chẩn đoán [2]. X-quang cắt lớp vi tính ngực là phương tiên phát hiện tổn thương thâm nhiếm tốt hơn so với $X$-quang ngực. Tuy nhiên việc chụp $X$-quang cắt lớp vi tính ngực thường quy (khi cần) gặp nhiều khó khăn do làm tăng chi phí điều trị, tăng phơi nhiễm với tia phóng xạ và đặc biệt là không thể thực hiện tại giường cho nhửng bệnh nhi bị viêm phổi nă̆ng.

Những hạn chế của $X$-quang và $X$-quang cắt lớp vi tính ngực nêu trên đã thúc đẩy việc tìm ra một kĩ thuâtt mới để chẩn đoán viêm phổi ở trẻ em. Trong những năm gần đây, có nhiêu tác giả đã nghiên cứu đánh giá vai trò của siêu âm trong chẩn đoán viêm phổi cũng như biến chứng của viêm phổi và thu được những kết quả khả 
quan nhất định. Khả năng chẩn đoán của siêu âm trong các nghiên cứu trên đạt tới độ nhạy $95 \%-97 \%$, độ đặc hiệu $90 \%-94 \%$. Cùng với đó siêu âm phổi có thể thực hiện tại giường, làm lại nhiều lần, cho kết quả ngay và không bị phơi nhiễm với tia phóng xạ.

Vì vâyy chúng tôi tiến hành nghiên cứu đề tài này nhằm: Xác định giá trị của siêu âm phổi trong chẩn đoán viêm phổi có biến chứng ở trẻ em (đối chiếu với $X$-quang cắt lớp vi tính là tiêu chuẩn vàng chẩn đoán).

\section{II. ĐỐI TƯƠNG VÀ PHƯƠNG PHÁP NGHIÊN CỨU}

2.1. Đối tướng nghiên cứu. Dân số chọn mẫu là những đối tượng bệnh nhân ở trên được chẩn đoán viêm phổi tại khoa Hô hấp và các khoa khác tại Bênh viện Nhi đồng I - Thành phố Hồ Chí Minh từ tháng 9/2018 đến tháng 7/2019.

Tiêu chuẩn chơn bệnh nhân: Bệnh nhân $\leq 15$ tuổi được chẩn đoán viêm phổi theo tiêu chuẩn của WHO (2013) [4]: Ho xuất tiết đờm. Nhịp thở nhanh. Rút lõm lồng ngực, rút lõm cơ liên sườn nặng: khó thở nặng, tím tái, rối loạn nhịp thở, ngừng thở... Nghe phổi: ran ẩm nhỏ hạt, có thể kèm ran rít, ran ngáy... X-quang tim phổi: đám mờ to nhỏ không đều, rải rác 2 phổi, tập trung vùng rốn phổi cạnh tim 2 bên, có thể tập trung ở 1 thùy hoặc 1 phân thùy phổi.

Bệnh nhân được siêu âm phổi và chụp $X$ quang cắt lớp vi tính ngực. Thời gian bệnh nhân được siêu âm phổi và chụp X-quang CLVT ngực cách nhau trong khoảng từ $24-48$ giờ.

Kết quả siêu âm và chụp X-quang cắt lớp vi tính ngực phải mô tả đầy đủ các dấu hiệu tổn thương theo mẫu bệnh án nghiên cứu

Tiêu chuẩn loại trừ: Bệnh nhân không được chụp X-quang cắt lớp vi tính ngực hoặc được chụp nhưng quá thời gian quy định trong nghiên cứu (> 48 giờ kể từ khi siêu âm phổi). Bệnh nhân được siêu âm và chụp X-quang cắt lớp vi tính ngực nhưng kết quả không mô tả được đầy đủ các dấu hiệu tổn thương theo mẫu bệnh án nghiên cứu. Những bệnh nhân đủ tiêu chuẩn tham gia nghiên cứu nhưng bệnh nhân hoặc người thân trong gia đình bệnh nhân không đồng ý tham gia nghiên cứu.

\subsection{Phương pháp nghiên cứu}

Phương pháp nghiên cứu: nghiên cứu hồi cứu kết hợp tiến cứu (mô tả ca bênh)

Phương tiên nghiên cứu: Máy siêu âm hiệu Siemens tại bệnh viện Nhi Đồng 1, sử dụng 2 loại đầu dò: đầu dò cong (convex) tần số từ $3,5-5 \mathrm{MHz}$ và đâu dò thẳng (linear) tân số từ 7-
$12,5 \mathrm{MHz}$, kèm sử dụng Doppler màu nếu cần thiết. Máy chụp cắt lớp vi tính Somatom hiệu Philips 16 lát cắt.

Phương pháp tiến hành: Bệnh nhân được siêu âm phổi, sau đó được chụp X-quang CLVT ngực trong vòng từ $24-48$ giờ kể từ khi siêu âm phổi. Thu thập các thông tin liên quan đến bệnh sử của bệnh nhân trong quá trình điều trị tại bệnh viện và được ghi lại theo mẫu bệnh án chung. Đợ kết quả siêu âm và chụp $X$-quang CLVT ngực cho các bệnh nhân theo mẫu bệnh án nghiền cứu. Kết luận chẩn đoán xác định cuối cùng về viêm phổi cũng như các biến chứng của viêm phổi (tràn dịch màng phổi, tràn khí màng phổi, viêm phổi hoại tử, áp xe phổi và xẹp phổi) và vị trí của các biến chứng (phổi phải, phổi trái, hai phổi) dựa vào X-quang CLVT ngực.

Phương pháp thu thâap số liệu: Hồ sơ chẩn đoán ra viện là viêm phổi có biến chứng từ ngày bệnh nhân bị bệnh đến ngày bệnh nhân được siêu âm phổi và chụp X-quang CLVT ngực. Thu thập các biến lâm sàng: Dựa vào hồ sơ bệnh án để thu thập các thông tin về tuổi, giới, tình trạng cân nặng, chiều cao của các bệnh nhi. Các triệu chứng lâm sàng được thu thập dựa vào hồ sơ bệnh án theo bệnh án mẫu. Thu thập các biến trền X-quang CLVT: Các dấu hiệu tổn thương của các biến trên X-quang CLVT ngực được thu thập dựa vào kết quả đọc phim X-quang CLVT ngực của các bác sĩ chuyển khoa có kinh nghiệm theo mẫu bệnh án nghiên cứu. Thu thập các biến trên siêu âm: Các dấu hiệu tổn thương cũng như các biến trên siêu âm phổi được thu thập một cách độc lập với kết quả chụp X-quang CLVT, theo bệnh án mẫu.

Kết quả siêu âm phổi và kết quả đọc phim chụp X-quang CLVT là độc lập với nhau và không biết kết quả chẩn đoán của bệnh nhân trước khi làm các xét nghiệm này.

2.3. Xử lý số liệu. Số liệu được nhập bằng excel, xử lý và phẩn tích bằng phương pháp thống kê y học, sử dụng phần mềm SPSS 25.0

\section{KẾT QUẢ NGHIÊN CỨU}

Từ tháng 8 năm 2018 đễn tháng 7 năm 2019 có tất cả 53 ca được chọn vào nghiên cứu, tuy nhiên trong quá trình nghiên cứu chúng tôi chỉ chọn được 43 ca, có 10 bệnh nhân bị loại vì không đáp ứng đủ tiêu chuẩn lựa chọn (trong đó có 8 bệnh nhân là không được chụp X-quang CLVT ngực và 02 bệnh nhân X-quang CLVT ngực mô tả đủ các dấu hiệu tổn thương theo bệnh án mẫu). 


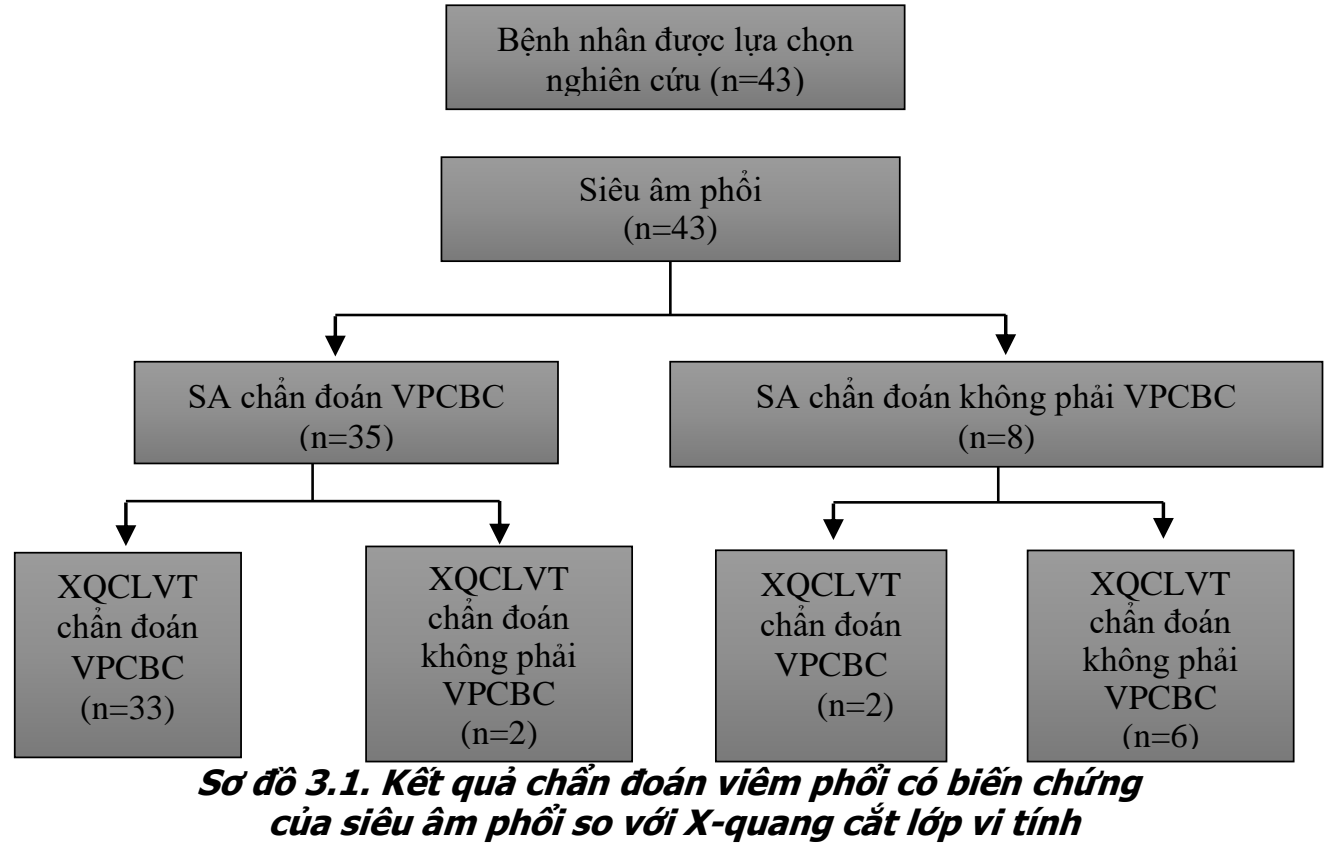

Bảng 3.1. Kêt quả chẩn đoán viêm phổi có biến chứng của siêu âm so với $X$-quang cắt lớp vi tính

\begin{tabular}{|c|c|c|c|c|}
\hline \multicolumn{2}{|c|}{} & \multicolumn{2}{|c|}{$\begin{array}{c}\text { X-quang CLVT } \\
\text { (VPCBC) }\end{array}$} & \multirow{2}{*}{ Cộng } \\
\cline { 3 - 4 } \multicolumn{2}{|c|}{} & Có & Không & \\
\hline \multirow{2}{*}{$\begin{array}{c}\text { Siêu âm } \\
\text { (VPCBC) }\end{array}$} & Có & 33 & 2 & 35 \\
\cline { 2 - 5 } & Không & 2 & 6 & 8 \\
\hline \multicolumn{2}{|c|}{ Cộng } & $\mathbf{3 5}$ & $\mathbf{8}$ & $\mathbf{4 3}$ \\
\hline
\end{tabular}

Nhân xét: $\mathrm{ÐN}=33 / 35=94,3 \% ; \mathrm{Ð} \mathrm{ÐH}=6 / 8=$ $75 \%$; GT $(+)=33 / 35=94,3 \%$; GT $(-)=6 / 8=75 \%$

Khi so sánh với tiêu chuẩn vàng là X-quang CLVT ngực trong chẩn đoán VPCBC, thì siêu âm có độ nhạy, độ đặc hiệu cao, với giá trị tương ứng lần lượt là: $94,3 \%$ và $75 \%$. Giá trị tiên đoán dương tính là 94,3\% và giá trị tiên đoán âm tính là $75 \%$.

Bảng 3.2. Kêt quả chẩn đoán viêm phổi có biến chứng tràn dịch màng phổi của siêu âm phổi so với X-quang cắt lớp vi tính

\begin{tabular}{|c|c|c|c|c|}
\hline \multirow{2}{*}{} & \multicolumn{2}{|c|}{$\begin{array}{c}\text { X-quang CLVT } \\
\text { (TDMP) }\end{array}$} & \multirow{2}{*}{ Cộng } \\
\cline { 2 - 5 } & Có & Không & \\
\hline Siêu âm & Có & 19 & 1 & 20 \\
\cline { 2 - 5 } (TDMP) & Không & 1 & 14 & 15 \\
\hline \multicolumn{2}{|c|}{ Cộng } & 20 & 15 & 35 \\
\hline \multicolumn{2}{|c|}{ AUC = 0,942 (CI 95\%: 0,849-1), p < $0,0001}$. \\
\hline
\end{tabular}

Nhân xét: $\mathrm{ĐN}=19 / 20=95 \% ; \mathrm{ÐH}=14 / 15$

$=93,3 \% ;$ GT $(+)=19 / 20=95 \% ;$ GT $(-)=$ $14 / 15=93,3 \%$

Siêu âm có độ nhạy, độ đặc hiệu cao trong chẩn đoán TDMP, với giá trị tương ứng lần lượt là: $95 \%$ và $93,3 \%$. Giá trị tiên đoán dương tính

là $95 \%$ và giá trị tiên đoán âm tính là 93,3\%. Siêu âm có giá trị rất tốt trong chẩn đoán TDMP ở bệnh nhân viêm phổi vì: Diện tích dưới đường cong $(A U C)=0,942$ (Khoảng tin cậy CI 95\%: $0,849-1), \mathrm{p}<0,0001$.

Bảng 3.3. Kết quả chẩn đoán viêm phổi có biến chứng tràn khí màng phổi của siêu âm phổi so với $X$-quang cắt lớp vi tính

\begin{tabular}{|c|c|c|c|c|}
\hline \multirow{2}{*}{\multicolumn{2}{|c|}{}} & \multicolumn{2}{|c|}{$\begin{array}{c}\text { X-quang CLVT } \\
\text { (TKM) }\end{array}$} & \multirow{2}{*}{ Cộng } \\
\cline { 3 - 4 } \multicolumn{2}{|c|}{} & Có & Không & \\
\hline \multirow{2}{*}{$\begin{array}{c}\text { Siêu âm } \\
\text { (TKMP) }\end{array}$} & Có & 5 & 0 & 5 \\
\cline { 2 - 4 } & Không & 1 & 29 & 30 \\
\hline \multicolumn{2}{|c|}{ Cộng } & 6 & 29 & 35 \\
\hline \multicolumn{2}{|c|}{ AUC }
\end{tabular}

AUC = 0,915 (CI 95\%: 0,738-1), p < 0,0001.

Nhân xét: $\mathrm{DN}=5 / 6=83,3 \% ; \mathrm{DDH}=29 / 29=$ $100 \%$; GT (+) = 5/5 = 100\%; GT (-) = 29/30 = 96,7\%

Khi so sánh với tiêu chuẩn vàng là $X$-quang CLVT ngực trong chẩn đoán tràn khí màng phổi ở bệnh nhân viêm phổi, thì siêu âm có độ nhạy, độ đặc hiệu cao, với giá trị tương ứng lần lượt là: $83,3 \%$ và $100 \%$. Giá trị tiên đoán dương tính là $100 \%$ và giá trị tiên đoán âm tính là $96,7 \%$. Siêu âm có giá trị rất tốt trong chẩn đoán TKMP ở bệnh nhân viêm phổi vì: Diện tích dưới đường cong $(A U C)=0,915$ (Khoảng tin cậy CI 95\%: $0,738-1), p<0,0001$.

Bảng 3.4. Kết quả chẩn đoán viêm phổi có biên chứng xêp phổi của siêu âm phổi so với $X$-quang cắt lớp vi tính

\begin{tabular}{|l|c|c|}
\hline & $\begin{array}{c}\text { X-quang CLVT } \\
\text { (Xẹp phổi) }\end{array}$ & \multirow{2}{*}{ Cộng } \\
\cline { 2 - 3 } & Có Không & \\
\hline
\end{tabular}




\begin{tabular}{|c|c|c|c|c|}
\hline Siêu âm & Có & 22 & 0 & 22 \\
\cline { 2 - 5 } (Xẹp phổi) & Không & 1 & 12 & 13 \\
\hline Cộng & 23 & 12 & 35 \\
\hline AUC $=0,978$ (CI 95\%: 0,928 - 1), p <0,0001. \\
\hline
\end{tabular}

Nhân xét: $\mathrm{ÐN}=22 / 23=95,7 \% ; \mathrm{ĐĐH}=$ $12 / 12=100 \% ;$ GT $(+)=22 / 22=100 \% ;$ GT $(-)$ $=12 / 13=92,3 \%$.

Siêu âm có độ nhạy cao $(95,7 \%)$, độ đặc hiệu cao $(100 \%)$. Giá trị tiên đoán dương tính là $100 \%$ và giá trị tiên đoán âm tính là $92,3 \%$. Siêu âm có giá trị rất tốt trong chẩn đoán xẹp phổi vì: Diện tích dưới đường cong (AUC) $=0,978$ (Khoảng tin cậy CI 95\%: 0,928 - 1), p< 0,0001.

Bảng 3.5. Kêt quả chẩn đoán viêm phổ có biến chứng viêm phổi hoai tứ của siêu âm phổi so với $X$-quang cắt lớp vi tính

\begin{tabular}{|l|c|c|c|c|}
\hline \multirow{2}{*}{} & \multicolumn{2}{|c|}{$\begin{array}{c}\text { X-quang CLVT } \\
\text { (VPHT) }\end{array}$} & \multirow{2}{*}{ Cộng } \\
\cline { 2 - 4 } \multicolumn{2}{|c|}{} & Có & Không & \\
\hline \multirow{2}{*}{$\begin{array}{c}\text { Siêu âm } \\
\text { (VPHT) }\end{array}$} & Cón & 14 & 0 & 14 \\
\hline \multicolumn{2}{|c|}{ Cộng } & 1 & 20 & 21 \\
\hline \multicolumn{2}{|c|}{ AUC $=0,942$ (CI 95\%: 0,849-1) p < 0,0001. } \\
\hline
\end{tabular}

Nhận xét: $\mathrm{ĐN}=14 / 15=93,3 \% ; \quad \mathrm{ĐH}=$ $20 / 20=100 \% ;$ GT $(+)=14 / 14=100 \%$; GT $(-)$ $=20 / 21=95,2 \%$

Khi so sánh với tiêu chuẩn vàng là $X$-quang CLVT ngực trong chẩn đoán VPHT ở bệnh nhân viêm phổi, thì siêu âm có độ nhạy, độ đặc hiệu cao, với giá trị tương ứng lần lượt là: $93,3 \%$ và $100 \%$. Giá trị tiên đoán dương tính là $100 \%$ và giá trị tiên đoán âm tính là $95,2 \%$. Siêu âm có giá trị rất tốt trong chẩn đoán VPHT ở bệnh nhân viêm phổi vì: Diện tích dưới đường cong $(A U C)=0,942$ (Khoảng tin cậy CI 95\%: 0,849 1) $p<0,0001$.

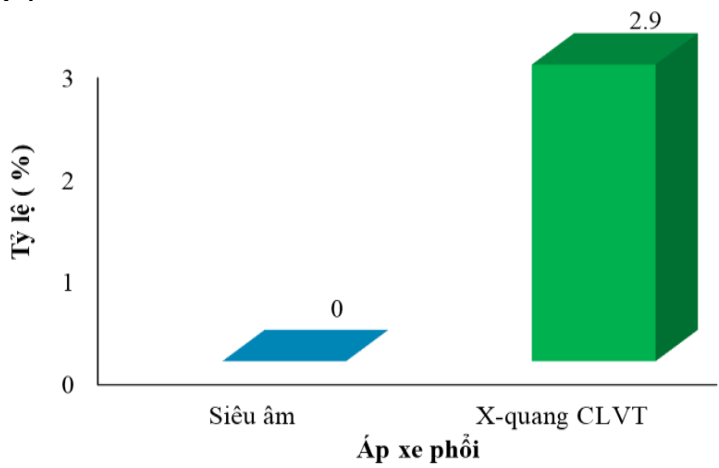

Biểu đồ 3.1. Tỷ lệ chẩn đoán viêm phổi có biến chứng áp xe của siêu âm so với $X$ quang cắt lớp vi tính

Nhận xét: Trong 35 bệnh nhân được chẩn đoán viêm phổi có biến chứng thì cả siêu âm và X-quang CLVT đều khẳng định được 34 trường hợp không bị áp xe phổi, chiếm tỷ lệ 97,1\%; chỉ có 1 trường hợp được chẩn đoán là viêm phổi có biến chứng áp xe phổi trên phim chụp X-quang CLVT ngực, chiếm tỷ lệ 2,9\% nhưng siêu âm phổi không phát hiện được.

\section{BÀN LUẬN}

Trong 43 bệnh nhân được chẩn đoán là viêm phổi bằng chụp X-quang CLVT ngực thì có 35/43 trường hợp được chẩn đoán là viêm phổi có biến chứng (Tràn dịch màng phổi, tràn khí màng phổi, viêm phổi hoại tử, áp xe phổi và xẹp phổi). Như vậy, theo kết quả chẩn đoán ở sơ đồ 3.1 cho thấy khi so sánh với tiêu chuẩn vàng là chụp X-quang CLVT ngực thì kết quả siêu âm phổi có hai trường hợp dương tính giả gồm một bệnh nhân nhược cơ, và một bệnh nhân phù phổi cấp.

Mặt khác, cũng theo kết quả ở sơ đồ 3.1 cho thãy, trong 8 bệnh nhân siêu âm phổi chẩn đoán không bị VPCBC thì có 2 trường hợp được chẩn đoán viêm phổi có biến chứng bằng chụp $X$ quang CLVT ngực. Đó là hai bệnh nhân có hình ảnh viêm phổi có biến chứng ở vị trí phía sau phổi trái được phát hiện dựa vào X-quang CLVT ngực. Điều này được lí giải do vị trí tổn thương phía sau phổi trái là vị trí dễ bị bỏ sót nhất trên siêu âm phổi. Khi đưa đầu dò từ trước ra sau, từ trên xuống dưới theo các vùng ở phổi trái thì có hai cấu trúc sẽ ảnh hưởng tới khả năng thăm khám của tia siêu âm là bóng tim ở trước và xương bả vai ở phía sau. Cả hai cấu trúc đều chiếm một phần bề mặt nhu mô phổi khiến cửa số thăm khám của siêu âm bị hạn chế hơn. Kết quả 2 trường hợp âm tính giả trên có thể giải thích do ảnh hưởng của xương bả vai trái lên siêu âm phổi khi các vị trí tổn thương được phát hiện trên X-quang CLVT ngực nằm ở vùng phổi phía sau, dưới xương bả vai.

Kết quả chẩn đoán từng loại biến chứng của viêm phổi trên siêu âm sẽ được so sánh với Xquang CLVT ngực để từ đó tính giá trị của siêu âm trong chẩn đoán từng loại biến chứng của viêm phổi

4.1. Tràn dịch màng phổi. Trong nghiên cứu của chúng tổi siêu âm có độ nhạy là $95 \%$ và độ đặc hiệu là 93,3\% trong chẩn đoán TDMP ở bệnh nhân VPCBC. Giá trị tiên đoán dương tính, âm tính cũng ở mức rất cao với giá trị lần lượt là $95 \%$ và $93,3 \%$. Kết quả cho thấy $18 / 19$ trường hợp $(94,7 \%)$ đều được X-quang CLVT và siêu âm phát hiện TDMP, tuy nhiên siêu âm đánh giá tính chất dịch vách hóa tốt hơn [3].

Như vậy các kết quả nghiên cứu trên đều cho thấy siêu âm có độ nhạy độ, đặc hiệu rất cao 
trong chẩn đoán TDMP. Bên cạnh đó, siêu âm còn có thể giúp xác định được bản chất dịch. Qua đó góp phần định hướng cho việc xác định nguyên nhân gây TDMP.

4.2. Tràn khí màng phổi. Trong nghiên cứu của chúng tôi siêu âm có độ nhạy là $83,3 \%$ và độ đặc hiệu là $100 \%$ trong chẩn đoán TKMP ở bệnh nhân VPCBC. Giá trị tiên đoán dương tính, âm tính cũng ở mức rất cao với giá trị lần lượt là $100 \%$ và $96,7 \%$. Kết quả này tương tự kết quả nghiên cứu của tác giả Nagarsheth (2011), độ nhạy của siêu âm trong chẩn đoán TKMP là $81,8 \%$ và độ đặc hiệu là $100 \%$, giá trị tiên đoán âm tính của siêu âm trong chẩn đoán tràn khí màng phổi là 93,4\%.

Như vậy các kết quả nghiên cứu trên đều cho thấy mặc dù có sự khác nhau về giá trị của siêu âm trong chẩn đoán TKMP. Nhưng các nghiên cứu đều khẳng định siêu âm là một phương pháp chẩn đoán có độ nhạy độ, đặc hiệu rất cao trong chẩn đoán TKMP.

4.3. Xẹp phổi. Trong nghiên cứu của chúng tôi siêu âm có độ nhạy là $95,7 \%$ và độ đặc hiệu là $100 \%$ trong chẩn đoán xẹp phổi ở bệnh nhẩn VPCBC. Giá trị tiên đoán dương tính, âm tính cũng ở mức rất cao với giá trị lần lượt là $100 \%$ và 92,3\%. Tương tự, theo tác giả Yang (2009) [6], độ nhạy, độ đặc hiệu, giá trị tiên đoán dương tính, giá trị tiên đoán âm tính và độ chính xác của siêu âm trong chẩn đoán xẹp phổi lân lượt là $81,8 \%, 100 \%, 100 \%, 85,9 \%$ và $91,4 \%$.

Như vậy, mặc dù có sự khác nhau về kết quả nghiên cứu của siêu âm trong chẩn đoán xẹp phổi. Nhưng các nghiên cứu đều khẳng định siểu âm là một phương pháp chẩn đoán có độ nhạy độ, đặc hiệu rất cao trong chẩn đoán xẹp phổi.

4.4. Viêm phổi hoại tử. Kết quả nghiên cứu ở bảng 3.18 cho thây siêu âm có độ nhạy là $93,3 \%$ và độ đặc hiệu là $100 \%$ trong chẩn đoán VPHT ở bệnh nhân VPCBC. Giá trị tiên đoán dương tính, âm tính cũng ở mức rất cao với giá trị lần lượt là $100 \%$ và $95,2 \%$. Kết quả này là cao hơn kết quả nghiên cứu của tác giả Chiu (2008) [1], độ nhạy, độ đặc hiệu và giá trị tiên đoán dương tính của siêu âm trong chẩn đoán VPHT lần lượt là $35 \%, 100 \%$ và $100 \%$.

Như vậy các kết quả nghiên cứu trên đều cho thấy mặc dù có sự khác nhau về giá trị của siêu âm trong chẩn đoán VPHT. Nhưng các nghiên cứu đều khẳng định siêu âm là một phương pháp chẩn đoán có độ nhạy độ, đặc hiệu rất cao trong chẩn đoán VPHTं.

4.5. Áp xe phổi. Kết quả nghiên cứu ở biểu đồ 3.10 cho thấy có 1 trường hợp được chẩn đoán là áp xe phổi bằng X-quang CLVT, nhưng siêu âm lại không phát hiện ra.

Với những kết quả thu nhận được như trên, chúng tôi thấy rằng siêu âm phổi là một phương pháp chẩn đoán không xâm lấn, kinh tế hơn rất nhiều (giá thành bằng khoảng $1 / 10$ lần so với chụp X-quang CLVT ngực), bệnh nhân không phải chịu một liều lượng tia X-quang và lượng thuốc cản quang nhất định, có thể triển khai được ở những tuyến cơ sở. Điều quan trọng là các kết quả nghiên cứu trên cho thấy siểu âm phổi là một phương tiện chẩn đoán đáng tin cậy trong việc chẩn đoán viêm phổi cũng như các biến chứng của viêm phổi (TDMP, TKMP, xẹp phổi và VPHT). Nó giúp cho các nhà lâm sàng có thể chẩn đoán sớm, chính xác viêm phổi và biến chứng của viêm phổi, và giúp theo dõi diễn biến và kết quả của quá trình điều trị một cách thích hợp vì có thể kiểm tra lại nhiều lần ngay tại giường bệnh. Trong hầu hết các trường hợp, khám lâm sàng và siêu âm phổi là đủ để chẩn đoán. Tuy nhiên chúng ta phải cẩn thận trong trường hợp vị trí viêm phổi nơi siêu âm là khó nhìn thây. Mặt khác, như chúng ta cũng đã biết là kết quả chẩn đoán của siêu âm phổi phụ thuộc vào kinh nghiệm của người làm siêu âm rất nhiều nên việc đào tạo một cách bài bản cho tuyến cơ sở là điều hết sức cần thiết.

\section{KẾT LUẬN}

Siêu âm trong chẩn đoán viêm phổi biến chứng có độ nhạy, độ đặc hiệu cao (94,3\% và 75\%). Độ nhạy, độ đặc hiệu của siêu âm trong chẩn đoán từng loại biến chứng của viêm phổi là cao: tràn dịch màng phổi (độ nhạy: 95\%, độ đặc hiệu: 93,3\%), tràn khí màng phổi (độ nhạy: 83,3\%, độ đặc hiệu: 100\%), xẹp phổi (độ nhạy: $95,7 \%$, độ đặc hiệu: $100 \%$ ) và viêm phổi hoại tử (độ nhạy: 93,3\%, độ đặc hiệu: 100\%).

\section{TÀI LIÊU THAM KHẢO}

1. Chiu C-Y, Wong K-S, Lai S-H, et al. (2008), Peripheral hypoechoic spaces in consolidated lung: a specific diagnostic sonographic finding for necrotizing pneumonia in children, 50(1), pp.

2. Harris M, Clark J, Coote N, et al. (2011), British Thoracic Society guidelines for the management of community acquired pneumonia in children: update 2011, Thorax, 66 Suppl 2(pp. ii1-23.

3. Kurian J, Levin $T L$, Han BK, Taragin BH, Weinstein S (2009), Comparison of ultrasound and CT in the evaluation of pneumonia complicated by parapneumonic effusion in children, AJR Am J Roentgenol, 193(6), pp. 1648-54.

4. Organization WH, Pocket book of hospital care for children: guidelines for the management of common childhood illnesses. 2013: World Health Organization. 
5. Rudan I, Boschi-Pinto C, Biloglav Z, Mulholland K, Campbell H (2008), Epidemiology and etiology of childhood pneumonia, Bull World Health Organ, 86(5), pp. 408-16.

6. Yang J-x, Zhang M, Liu Z-h, et al. (2009),
Detection of lung atelectasis/consolidation by ultrasound in multiple trauma patients with mechanical ventilation, 1(1), pp. 13-16.

7. Châu NQ, Bệnh học nội khoa tâp I. 2012, NXB Y học Hà Nội: Trường Đại học Y Hà Nội. tr. 14-27.

\title{
ĐẶC ĐIỂM LÂM SÀNG VÀ TÌNH HÌNH ĐIỀU TRI ĐAU THẮT LƯNG TAI PHÒNG CHÂM CỨU NGOAI TRÚ BỆNH VIÊ̂N ĐA KHOA Y HỌC CỔ TRUYỀn HÀ NộI
}

\author{
Nguyễn Thị Thanh Tú*, Cao Thị Huyền Trang*, Nhữ Thị Thảo*
}

\section{TÓM TẮT}

Mục tiêu: Khảo sát đặc điểm lâm sàng và tình hình điều trị bệnh đau thắt lưng tại phòng Châm cứu ngoại trú - Bệnh viện Đa khoa Y học cổ truyền Hà Nội. Đối tượng và phương pháp: Nghiên cứu tiến cứu, mô tả cắt ngang. Chọn tất cả các bệnh nhân đau thắt lưng vào điều trị ngoại trú từ tháng 01/2019 đến tháng 09/2019. Kết quả: Trong thời gian nghiên cứu, phòng Châm cứu ngoại trú Bệnh viện Đa khoa đã điều trị cho 150 bệnh nhân. Về đặc điểm lâm sàng: bệnh nhân tập trung ở độ tuổi 30 - $39(34 \%)$, đa phần là nữ giới $(64,0 \%)$, lao động trí óc $(58,0 \%)$, thời gian mắc bệnh chủ yếu < 4 tuần $(72,0 \%)$, bệnh thường xuất hiện sau thay đổi thời tiết $(51,33 \%)$. Sau quá trình điều tri, số bênh nhân đõ chiếm tỉ lệ cao $(70 \%)$ và không có bệnh nhân nào nặng thêm. Kết luận: Nghiên cứu đã cung cấp những thông tin liên quan đến đặc điểm lâm sàng và tình hình điều trị bệnh ĐTL, giúp lẳnh đao phòng nhìn nhân tổng quát, đầy đủ vế bệnh để có thể đa dạng hơn các phương pháp điều trị cững như nâng cao hiệu quả điều trị.

Tư khóa: Đau thắt lưng, đặc điểm lâm sàng, tình hình điều trị

SUMMARY

CLINICAL CHARACTERISTICS AND

TREATMENT SITUATION OF LOW BACK

PAIN DISEASE AT THE OUTPATIENT

ACUPUNCTURE CLINIC - HANOI GENERAL

HOSPITAL OF TRADITIONAL MEDICINE

Objectives: To analyze the clinical characteristics and the treatment situation of the low back pain disease at the Outpatient acupuncture clinic, Hanoi General Hospital of Trditional Medicine. Subjects and Methods: Prospective cross-sectional study. Enrolled all patients admitted to the Outpatient clinic from January to September 2019. Results: In the study duration, the outpatient acupuncture clinic treated 150 low back pain patients. For the clinical characteristics:

*Trường Đại học Y Hà Nội

Chịu trách nhiệm chính: Nguyễn Thị Thanh Tú

Email: thanhtu@hmu.edu.vn

Ngày nhận bài: 2.3.2021

Ngày phản biên khoa học: 27.4.2021

Ngày duyệt bài: 11.5.2021
$34 \%$ of the patients in our study aged from $30-39$, $64 \%$ were female, $58 \%$ worked in the manual labor fields, most of whom had the durations of this disease less than 4 weeks (72\%), thí disease ususally occurred when the climate changed $(51,33 \%)$. After treatment, $70 \%$ of the patients had improved outcomes, no patients had worse outcome. Conclusions: This study has provided the information relating to the clinical characteristics and the treatment situation of the low back pain disease. These results help the managers to diversify the treatment therapies, enhancing the treatment results.

Keywords: low back pain, clinical, treatment

\section{I. ĐĂT VẤN ĐỀ}

Đau thắt lưng (ĐTL) hay còn gọ là đau lưng vùng thấp (Low back pain) là hội chứng đau khu trú trong khoảng từ ngang mức L1 đến nếp lằn mông [4]. Đây là một hội chứng xương khớp hay găp nhất trong thực hành lâm sàng. Nghiên cứu phỏng vấn sức khỏe quốc gia Hoa Kỳ năm 2002 cho thấy $26,4 \%$ trong số 30.000 người tham gia đã trải qua ít nhất một ngày đau lưng trong thời gian 3 tháng. Tại Việt Nam, tỷ lệ ĐTL chiếm 12\% trong nhân dân, chiếm 17\% những người trên 60 tuổi; chiếm 6\% tổng số các bệnh xương khớp [1]. Theo thống kê năm 2016 - 2017, tại phòng Châm cứu ngoại trú bệnh viện Đa khoa YHCT Hà Nội tỉ lệ bệnh nhân ĐTL đến điều trị đứng thứ 2 trong số các bệnh được điều trị [3]. Với mong muốn có cái nhìn tổng quát về bệnh nhân đau thắt lưng, từ đó đưa ra các phương pháp điều trị có hiệu quả hơn nữa, chúng tôi tiến hành nghiên cứu đề tài với hai mục tiêu sau:

1. Khảo sát đặc điểm lâm sàng của bệnh nhân đau thắt lưng điều trị tại phòng Châm cứu ngoại trú - Bv Đa khoa Y hoc cổ truyền Hà Nôii.

2. Khảo sát tình hinh điều trị đau thắt lưng tại phòng Châm cứu ngoại trú - Bệnh viện Đa khoa Y học cổ truyền Hà Nội.

\section{II. ĐỐI TƯợNG VÀ PHƯƠNG PHÁP NGHIÊN CỨU 2.1. Đối tượng nghiên cứu \\ + Tiêu chuẩn lựa chọn: Bệnh nhân được}

